Proceedings of the II Symposium on Applied Nuclear Physics and Innovative Technologies, Kraków, September 24-27, 2014

\title{
A Simple Approach to Data Analysis for the Detection of Hazardous Materials by Means of Neutron Activation Analysis
}

\author{
Ł. Kaźmierczak*, S. Borsuk, M. Gierlik, Z. Guzik, J. Iwanowska-Hanke,
} S. Korolczuk, T. KozŁowski, T. Krakowski, R. Marcinkowski, L. Swiderski, M. SZEPTYCKA, J. SzEWIŃSKI AND A. URBAN

National Centre for Nuclear Research, A. Sołtana 7, 05-400 Otwock-Świerk, Poland

\begin{abstract}
Neutron activation analysis is a well-known method for determining isotopic composition of different materials. Due to the non-destructive nature of the method it can also be used in homeland security application, for example an inspection of packages of unknown origin. For this purpose hazardous material detection system (SWAN) was built. The device has an automatic decision algorithm that analyze the spectrum of gamma rays of ${ }^{12} \mathrm{C},{ }^{14} \mathrm{~N}$ and ${ }^{16} \mathrm{O}$. Characteristic ratio of these lines gives the requested answer. Using such a simple approach SWAN is able to obtain promising results.
\end{abstract}

DOI: 10.12693 /APhysPolA.127.1540

PACS: $29.85 . \mathrm{Fj}$

\section{Introduction}

The hazardous materials detection system (SWAN) is a mobile device designed for the detection of explosives concealed in containers and interrogated with neutrons. SWAN is the result of the "Accelerators and Detectors" project at the National Centre for Nuclear Research [1]. It is a real time analyzer with dedicated software and electronics that distinguishes explosive materials from neutral ones in a matter of few minutes. The entire detection system is presented in Fig. 1 [2]. Analysed samples are activated by continuous flux of $14 \mathrm{MeV}$ neutrons and characteristic gamma rays spectrum is observed. Eventually, the isotopes identification and threat classification is performed.

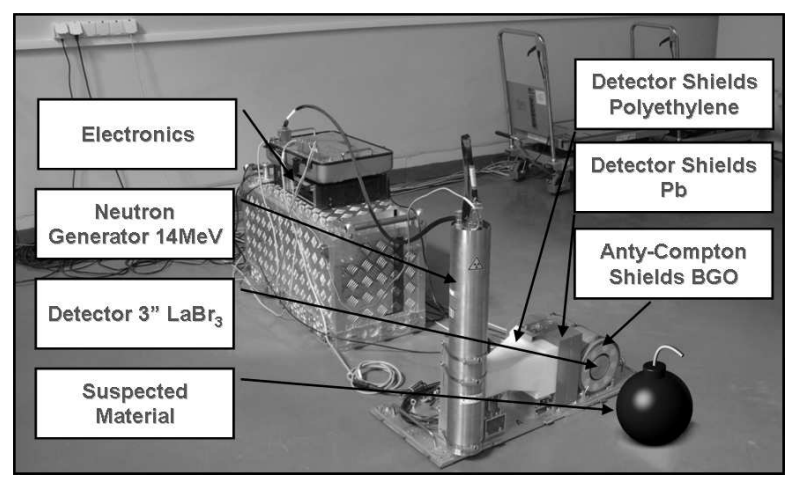

Fig. 1. The main parts of SWAN consist of the neutron generator, the spectroscopy detector $3 / \prime \times 3 / \prime \mathrm{LaBr}_{3}$, the anty-Compton shield (BGO), a VME rack with the acquisition board, a power supply, the computer, and the detector radiation shielding.

\footnotetext{
* corresponding author; e-mail: lukasz.kazmierczak@ncbj.gov.pl
}

\section{Analysis approach principles}

The majority of organic explosives and drugs have a similar, isotopic structure. They always contain carbon, nitrogen and oxygen but in various ratios. Relations of oxygen to carbon $\mathrm{O} / \mathrm{C}$ and nitrogen to carbon $\mathrm{N} / \mathrm{C}$ are characteristic for different groups of materials. Explosives have high content of oxygen and nitrogen with low content of hydrogen and carbon, whereas these relations in drugs are inverted [3]. The distinctive isotopic ratios of $\mathrm{O} / \mathrm{C}$ and $\mathrm{N} / \mathrm{C}$ for hazardous materials are well known and are shown in Fig. 2. Three groups of different materials: explosives, drugs, and neutral are mostly separated. This dependence is crucial for the

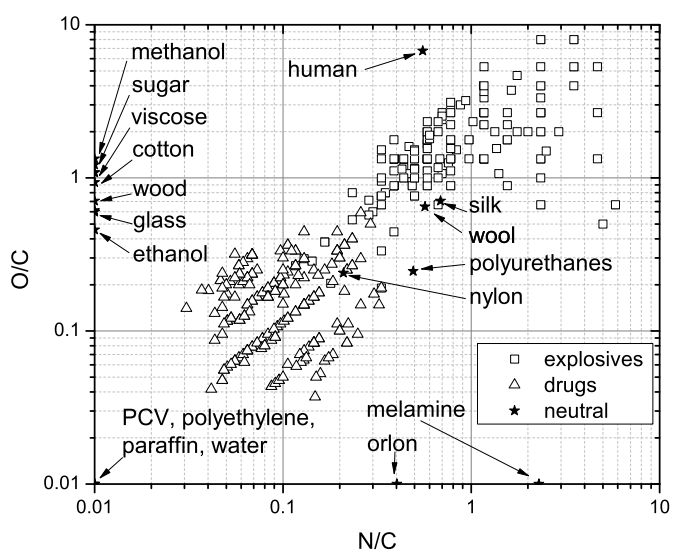

Fig. 2. Characteristic ratios $\mathrm{O} / \mathrm{C}$ and $\mathrm{N} / \mathrm{C}$ of hazardous materials; explosives and drugs compared to neutral ones. Both axes are in log scale. Points located directly on the $y$-axis do not containt oxygen and points located on the $x$-axis do not contain nitrogen. To improve the readability of the figure, the values of the corresponding coordinates have been changed to 0.01 . 
method since it enables separation of hazardous materials from neutrals. For example, all materials from Table I can be distinguished on the basis of characteristic ratios. Neutron activation analysis (NAA) method applied in SWAN provides the information about contents of ${ }^{12} \mathrm{C}$, ${ }^{14} \mathrm{~N},{ }^{16} \mathrm{O}$ isotopes in examined samples. In Table II the nuclear reactions of interest for the detection of explosives are shown [4]. We present part of gamma spectrum collected by SWAN in Fig. 3. Three lines of the isotopes mentioned above are clearly visible. We used this data to calculate the characteristic ratios.

TABLE I

Stoichiometric formulae and characteristic ratios for various materials.

\begin{tabular}{c|c|c|c|c}
\hline \hline Full name & Short name & Formulae [5] & $\mathrm{N} / \mathrm{C}$ & $\mathrm{O} / \mathrm{C}$ \\
\hline trinitrotoluene & TNT & $\mathrm{C}_{7} \mathrm{H}_{5} \mathrm{~N}_{3} \mathrm{O}_{5}$ & 0.5 & 1.14 \\
hexogen & RDX & $\mathrm{C}_{3} \mathrm{H}_{6} \mathrm{~N}_{6} \mathrm{O}_{6}$ & 2.33 & 2.37 \\
heroine & HER & $\mathrm{C}_{21} \mathrm{H}_{23} \mathrm{NO}_{5}$ & 0.06 & 0.32 \\
wool & WOL & - & 0.57 & 0.65
\end{tabular}

TABLE II

Nuclear reactions of interest for the identification of explosives.

\begin{tabular}{c|c|c|c}
\hline \hline Element & $\begin{array}{c}\text { Gamma energy } \\
{[\mathrm{MeV}]}\end{array}$ & $\begin{array}{c}\text { Cross-section } \\
{[\mathrm{mb}]}\end{array}$ & Reaction \\
\hline $\mathrm{C}$ & 4.439 & 211 & ${ }^{12} \mathrm{C}\left(\mathrm{n}, \mathrm{n}^{\prime} \gamma\right)^{12} \mathrm{C}$ \\
$\mathrm{N}$ & 5.106 & 44 & ${ }^{14} \mathrm{~N}\left(\mathrm{n}, \mathrm{n}^{\prime} \gamma\right)^{14} \mathrm{~N}$ \\
$\mathrm{O}$ & 6.130 & 167 & ${ }^{16} \mathrm{O}\left(\mathrm{n}, \mathrm{n}^{\prime} \gamma\right)^{16} \mathrm{O}$
\end{tabular}

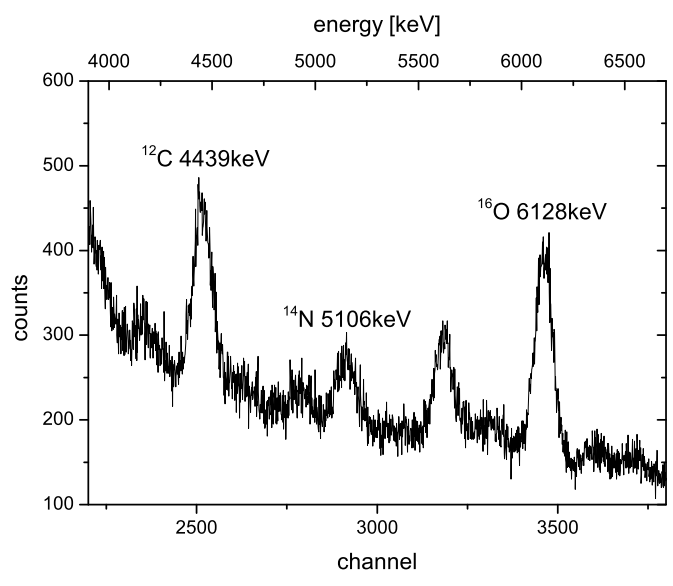

Fig. 3. Part of gamma spectra of TNT (Finger Prints) collected by SWAN during activation with $14 \mathrm{MeV}$ neutrons. Neutron flux was $3.3 \times 10^{8} \mathrm{n} / \mathrm{s}$, and the measurement life time was $600 \mathrm{~s}$.

\section{Experimental setup}

During the construction of the device, hazardous materials were needed for tests. As we do not have permanent access to them we created the "Finger Prints" mixtures which simulate explosives and drugs [6]. NAA analyses only the isotopic composition of the examinated materials. Hazardous materials are mostly composed of carbon, nitrogen, and oxygen, therefore we mixed various substances in appropriate stoichiometric ratios of $\mathrm{O} / \mathrm{C}$ and $\mathrm{N} / \mathrm{C}$. We used graphite as the carbon source, water as the oxygen source and melamine as the nitrogen source. For ensuring mixture homogeneity we used hydrogel, which easily merges with water. Finger Prints were very good replacements for hazardous materials. Prepared samples did not have chemical properties of real explosives or drugs, therefore they were harmless. Most of the algorithms' tests were performed with four Finger Prints mixtures. Promising preliminary results allowed for short tests with real explosives.

\section{Data analysis}

In the applied method the authors required reference gamma spectra of carbon, nitrogen, and oxygen for comparison with the spectrum of an examined sample. Those spectra were obtained through irradiation of the reference samples. To find the reference gamma spectrum of carbon a graphite sample was activated with $14 \mathrm{MeV}$ neutrons. Furthermore, authors interrogated the liquid nitrogen and water to get the reference spectra of respectively nitrogen and oxygen. We placed samples in identical containers and irradiated them one by one with neutrons. After that an empty container was irradiated to get the background level. It was then subtracted from the reference spectra. In the CNO matrix (1) we placed lines presented in Table II, measured for each of the reference spectra. Subsequent columns of the CNO matrix contain the reference spectra and the rows correspond to the described lines. For example, $\mathrm{C}_{\mathrm{O}}$ refers to the oxygen line from the reference spectrum of carbon. We carried out the same set of procedures with the suspected material and we placed measured lines $\mathrm{X}_{\mathrm{C}, \mathrm{N}, \mathrm{O}}$ in the vector $\bar{X}(1)$. The lines of ${ }^{1} \mathrm{H},{ }^{12} \mathrm{C},{ }^{16} \mathrm{O}$ and ${ }^{208} \mathrm{~Pb}$ are always visible in the gamma spectra. The energy calibration was performed for each measurement taking these lines as reference points. The dedicated algorithm automatically computed the energy calibration for each of those spectra. The decomposition procedure started after the energy calibration computation. Let us assume that

$$
\left[\begin{array}{ccc}
\mathrm{C}_{\mathrm{C}} & \mathrm{N}_{\mathrm{C}} & \mathrm{O}_{\mathrm{C}} \\
\mathrm{C}_{\mathrm{N}} & \mathrm{N}_{\mathrm{N}} & \mathrm{O}_{\mathrm{N}} \\
\mathrm{C}_{\mathrm{O}} & \mathrm{N}_{\mathrm{O}} & \mathrm{O}_{\mathrm{O}}
\end{array}\right]\left[\begin{array}{l}
\alpha_{\mathrm{C}} \\
\alpha_{\mathrm{N}} \\
\alpha_{\mathrm{O}}
\end{array}\right]=\left[\begin{array}{l}
\mathrm{X}_{\mathrm{C}} \\
\mathrm{X}_{\mathrm{N}} \\
\mathrm{X}_{\mathrm{O}}
\end{array}\right] .
$$

A simple transformation is needed to solve the following equation:

$$
\bar{\alpha}=\mathrm{CNO}^{-1} \bar{X} \text {. }
$$

A numerical analysis library Alglib was used to find the solution [7]. The authors performed the threat classification by determining characteristic ratios of $\mathrm{O} / \mathrm{C}$ and $\mathrm{N} / \mathrm{C}$ that were obtained by solving Eq. (2).

\section{Results and discussion}

The results of interrogation of four Finger Prints with $14 \mathrm{MeV}$ neutrons are presented in Fig. 4. We placed 
the sample in about $1 \mathrm{~cm}$ distance from the front of the detector. Neutron flux was $3.3 \times 10^{8} \mathrm{n} / \mathrm{s}$ and the measurement live time was $600 \mathrm{~s}$. Each sample was irradiated this way 36 times. Masses of the investigated mixtures were as follow: $700 \mathrm{~g}$ of HER, $1100 \mathrm{~g}$ of RDX, $700 \mathrm{~g}$ of TNT, and $1000 \mathrm{~g}$ of WOL. Theoretical values presented in Fig. 4 were calculated on the basis of stoichiometric formulae of investigated samples, whereas the hazardous areas (explosives and drugs) were calculated on the basis of data in Fig. 2. We present the detailed data of threat classification in Table III.

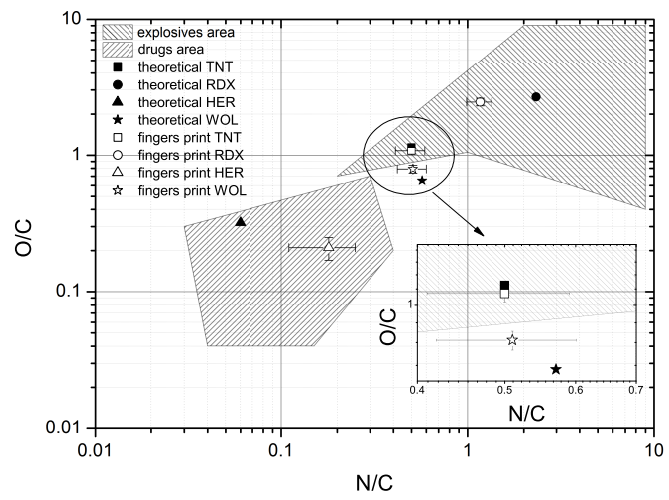

Fig. 4. The results for the four Finger Prints compared with the theoretical values. Inset contains magnification to improve the readability of TNT and WOL area.

\section{TABLE III}

Results of threat classification after 36 measurements of each Finger Prints mixture.

\begin{tabular}{c|c|c}
\hline \hline Short name & True recognition & False recognition \\
\hline TNT & $97 \%$ & $3 \%$ false negative \\
RDX & $94 \%$ & $6 \%$ false negative \\
HER & $100 \%$ & - \\
WOL & $92 \%$ & $8 \%$ false positive
\end{tabular}

As the results with Finger Prints were promising, the real explosives have been interrogated. We present the results of the research in Fig. 5. The distance from the front of the detector, neutron flux and life time were as described earlier. Each sample was irradiated once. Masses of the investigated mixtures were as follow: $170 \mathrm{~g}$ of TNT, $120 \mathrm{~g}$ of RDX, and about $690 \mathrm{~g}$ of several small packages of various explosives. The calculations for all investigated real explosives gave points in the danger area so it allows to conclude that all materials were explosives. Furthermore, the determined values of the $\mathrm{O} / \mathrm{C}$ and $\mathrm{N} / \mathrm{C}$ ratios for the real explosives and their Finger Prints are very similar. It means that our four Finger Prints mixtures are a good replacement of various hazardous materials. Performed tests demonstrated that $\mathrm{O} / \mathrm{C}$ ratio can be calculated more precisely than $\mathrm{N} / \mathrm{C}$ ratio. This is because reaction of ${ }^{14} \mathrm{~N}$ described in Table II have a smaller cross-section than reactions of ${ }^{16} \mathrm{O}$ and ${ }^{12} \mathrm{C}$ and it is strongly mixed with the line $5161 \mathrm{keV}$. This line comes from ${ }^{139} \mathrm{La}$. It is a total internal absorption in $\mathrm{LaBr}_{3}$. Nitrogen line is also mixed with the second escape peak from the strong line $6128 \mathrm{keV}$ of ${ }^{16} \mathrm{O}$.

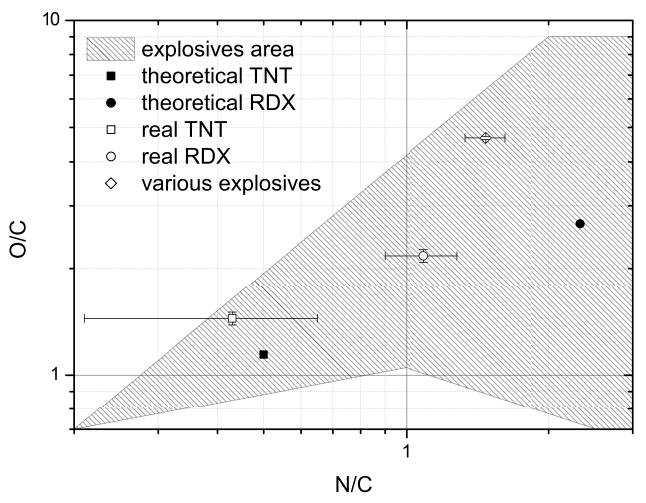

Fig. 5. The results for real explosives compared with the theoretical values.

\section{Conclusions}

SWAN explosives identification is performed on the basis of a very simple algorithm which effectiveness was proved in a laboratory environment. It correctly identifies real explosives and their random mixtures but it needs further development in order to increase its accuracy. This can be achieved by improving methods of nitrogen content estimation. Nevertheless, the achieved results are promising and form a good basis for further research.

\section{Acknowledgments}

This work is supported by EU Structural Funds Project no POIG.01.01.02-14-012/08-00.

\section{References}

[1] http://aid.ncbj.gov.pl/index.php/en/products/swan.

[2] M. Gierlik, S. Borsuk, Z. Guzik, J. Iwanowska, Ł. Kaźmierczak, S. Korolczuk, T. Kozłowski, T. Krakowski, R. Marcinkowski, L. Swiderski, M. Szeptycka, J. Szewiński, A. Urban, Nucl. Instrum. Methods Phys. Res. A 788, 54 (2015).

[3] G. Vourvopoulos, Chem. Ind.-London 297, 1994.

[4] W.V. Nunes, A.X. da Silva, V.R. Crispim, R. Schirru, Appl. Radiat. Isot. 56, 937 (2002).

[5] https://pubchem.ncbi.nlm.nih.gov.

[6] The patent application P-401747.

[7] http://www.alglib.net. 